\title{
Land fragmentation analysis using morphometric parameters
}

\author{
Jędrzej Gąsiorowski ${ }^{\mathrm{a}}$, Elżbieta Bielecka ${ }^{\mathrm{b}}$ \\ ${ }^{a}$ Institute of Geodesy and Cartography, Modzelewskiego 27, 02-679 Warsaw, Poland \\ ${ }^{b}$ Military University of Technology, Faculty of Civil Engineering and Geodesy, Kaliskiego 2, 00-908 Warsaw, Poland
}

\begin{abstract}
The article introduces the morphometric parcel analysis, which was performed for the four villages located in the central and southern part of Poland. These areas due to environmental and topographical conditions are characterized by a relatively high land fragmentation. The area of the parcels ranges from $45 \mathrm{~m}^{2}$ to 68 hectares. The study included the analysis of area and shape of the parcels, the distance from the human habitats, and the manner of land use on the parcels. The correlation between the various factors was examined for the individual villages. It revealed, that there exist relationships between shape, slope and way of land use on the parcel and became the basis for proposing of the morphometric index, which allows for assessing geometric characteristics degree of the parcels and the land fragmentation. Morphometric analysis of parcels is interesting in many fields of spatial sciences including land management on rural areas. The article provides a contribution to an area-wide quantitative statistical description and classification of morphometric parameters such as shape, area and slope of existing agricultural parcels. Research is based on geodata from the Lands and Buildings Register in Poland, which constitutes a part of cadastral system.
\end{abstract}

Keywords: shape index; land management; spatial structure; land fragmentation.

\begin{tabular}{|ll|}
\hline Nomenclature \\
PA & parcel area \\
SI & shape index \\
NoBP & number of boundary points \\
DoP & dispersion of parcels \\
PoAL & percentage of agriculture land \\
PoBL & percentage of built-up land \\
PPoH & parcel percentage of total holding area \\
\hline
\end{tabular}

\section{Introduction}

Land fragmentation is a major problem in many countries around the world, also in Poland. According to the Ministry of Agriculture and Rural Development reports about 2 million $\mathrm{km}^{2}$ of agricultural land have inappropriate structure and need consolidation. This number - according to many practitioners and researchers - is almost twice bigger. Therefore, there are big needs for land consolidation in Poland. At the other hand land consolidation works in Poland continually falls (in the years 2000-2011 only 114.5 thousand $\mathrm{km}^{2}$ were consolidated) what is caused by lack of funds, complicated procedure, and lack of synthetic quantitative indexes, which allow for the assessment of land fragmentation.

Land fragmentation, alternatively named by Bentley as pulverization, parcellization or scattering [1], is defined as a situation where a farming household possesses several non-contiguous land plots, often scattered over a wide area. It is an observed phenomenon in many countries around the world, and is generally viewed as an obstacle to agricultural productivity and modernization [2-3]. Many researchers consider land fragmentation as a serious obstacle to optimal agricultural development because it hinders mechanization, causes inefficient production and involves large costs to alleviate the adverse effects, resulting in a reduction in farmers' net incomes [4-7].

Land fragmentation harms land productivity in a number of ways [8]. Fragmented land holdings can increase transport costs and might also cause difficulties to grow certain crops, and prevent farmers from changing to high profit crops. Other

Corresponding author: Jędrzej Gąsiorowski. E-mail address: jedrzej.gasiorowski@igik.edu.pl

http://dx.doi.org/10.3846/enviro.2014.205

(C) 2014 The Authors. Published by VGTU Press. This is an open-access article distributed under the terms of the Creative Commons Attribution License, which permits unrestricted use, distribution, and reproduction in any medium, provided the original author and source are credited. 
costs associated with land fragmentation include the hindering of economies of scale and farm mechanization. Small and scattered plots hamper the use of machinery and other large scale agricultural practices. In small fields operating machines and moving them from one field to another can cause problems. Small land holdings might also discourage the development of infrastructure like transportation, communication, irrigation, and drainage. Finally it is noticed that banks are sometimes unwilling to take small, scattered land holdings as collateral, which prevents farmers from obtaining credit to make investments.

Even though policy makers often point out the drawbacks of fragmentation there is no consensus that fragmentation is strictly a negative phenomenon [9-10]. Bentley [1] argues that many different plots allow farmers access to land of different qualities when it comes to soil, slope, micro-climatic variations etc. In addition, a holding with several plots facilitates crop rotation and the ability to leave some land fallow. Pasakarnis et al. [11-12] argued that enlargement of arable plots has negative consequences on cultural landscapes, because it leads to more homogeneous landscape and the loss of cultural value. Moreover, there is a justified concern that land consolidation contributes towards the impoverishment, sometimes even destruction of Polish traditional agrarian landscape pattern, which is unique throughout the European Union countries.

According to findings of King and Burton [4] land fragmentation is associated with six factors:

- the landholding size;

- the number of parcels belonging to the holding;

- the size of each parcel;

- the shape of each parcel;

- the spatial distribution of parcels;

- the size distribution of the parcels.

As many factors are involved, some authors $[1,10]$ concluded that there appears to be no standard or comprehensive measure of land fragmentation. According to the research conducted by Dementroiu et al. $[9,13]$ most authors have utilised a simple uni-variate fragmentation measure such as the average number of parcels per holding or the average holding size or the average parcel size at the regional or national level. These land fragmentation measures are morphometric parameter as they encompass quantitative analysis of form, namely size and shape.

Morphometric analysis of parcels is interesting in many fields of spatial sciences including land management on rural areas. The article provides a contribution to an area-wide quantitative statistical description and classification of morphometric parameters such as shape, area and slope of existing agricultural parcels. Research is based on geodata from the Lands and Buildings Register in Poland, which constitutes a part of cadastral system.

\section{Land fragmentation in Poland}

Land Many rural areas of European countries suffer from land fragmentation, however, this problem is really acute in Central and Eastern Europe [14], where Poland stands out from other countries. The agrarian pattern in Poland has always been characterized by high fragmentation. It is a consequence of farmland reforms that have been taken place over the postwar period. At the beginning of the 90's transition from central managed to market economy led up to increase the level of land disintegration. Large-sized farms, being previously under state management, had been split up into a large number of approximately one hectare plots and purchased by great deal of private owners. This resulted that $40 \%$ of all agricultural land is used in units smaller than 2 ha. The share of small-scale family farms in Poland, with area less than 1 ha, is about $26 \%$, where large holdings, occupying more than 50 ha, take only $1.2 \%$ [15]. According to the Ministry of Agriculture and Rural Development reports [16] about 2 million $\mathrm{km} 2$ of agricultural land have inappropriate structure and need consolidation. This number - according to many practitioners and researchers - is almost twice bigger. The smallest farms are mainly located in the south-eastern part of Poland, in voivodeships: Małopolskie, Podkarpackie and Lubelskie. In contrast the most favourable agrarian structure occurs within northern and western Poland.

The fragmentation of agricultural land in Poland is mainly the result of: inheritance division, land purchase, and also diverse topography, which is the main obstacle in mountain regions, as well as the soil diversity, especially troublesome in lowlands.

\section{Case study}

The morphometric parcel analysis was performed for the four villages located in the central and southern part of Poland (Fig. 1). These areas due to historical, cultural, environmental and topographical conditions are characterized by a diverse land fragmentation and vary from low- to high-fragmented. Main characteristic of the analyzed villages is given in Table 1.

The areas of high land fragmentation are characterized by the large number of parcels per area unit and large number of holdings per area unit. Therefore, on the basis of the above characteristics and the visual assessment of parcel layout in the villages (Fig. 2), they can be ordered from the highest to the lowest fragmentation in the following sequence: Rudołowice, Marysinek, Grabal, Krajów. 


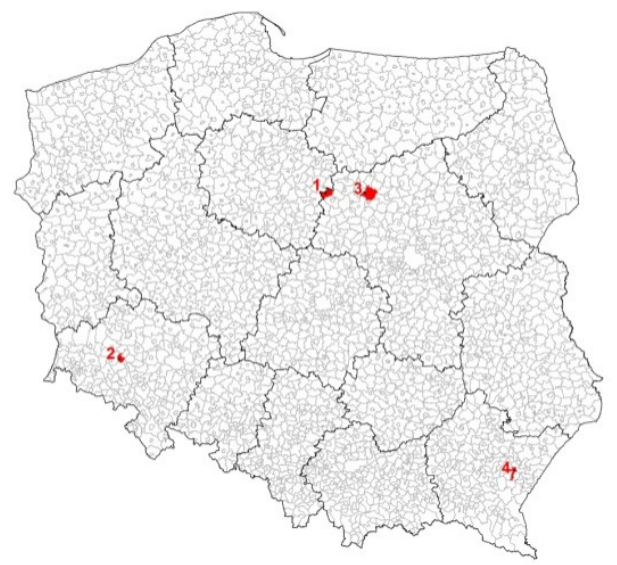

Fig. 1. The study area: 1-Grabal; 2 - Krajów; 3 - Marysinek; 4 - Rudołowice

Table 1. Main characteristic of the study area

\begin{tabular}{lllll}
\hline & Krajów & Grabal & Marysinek & Rudołowice \\
\hline Voivodship & dolnośląskie & mazowieckie & mazowieckie & podkarpackie \\
Area [ha] & 535.63 & 257.73 & 412.48 & 774.02 \\
Perimeter [m] & 11472 & 9521 & 13083 & 12020 \\
Hmin -min altitude [m] & 129 & 109 & 105 & 79 \\
Hmax -max altitude [m] & 319 & 129 & 131 & 221 \\
$\Delta \mathrm{h}=$ Hmin - Hmax [m] & 190 & 22 & 26 & 142 \\
No. of land parcels & 116 & 85 & 254 & 498 \\
No. of holdings & 35 & 32 & 62 & 270 \\
Average area of parcel $\left[\mathrm{m}^{2}\right]$ & 34294 & 25546 & 17995 & 6452 \\
Minimum parcel area $\left[\mathrm{m}^{2}\right]$ & 165 & 308 & 200 & 101 \\
Maximum parcel area $\left[\mathrm{m}^{2}\right]$ & 678293 & 164850 & 146172 & 344799 \\
Minimum holding area $[\mathrm{ha}]$ & 0.07 & 0.25 & 0.13 & 0.04 \\
Maximum holding area $[\mathrm{ha}]$ & 158.11 & 28.01 & 24.79 & 39.08 \\
Average parcel no. per holding $\left[\mathrm{m}^{2}\right]$ & 3.3 & 2.7 & 4.1 & 1.8 \\
\hline
\end{tabular}

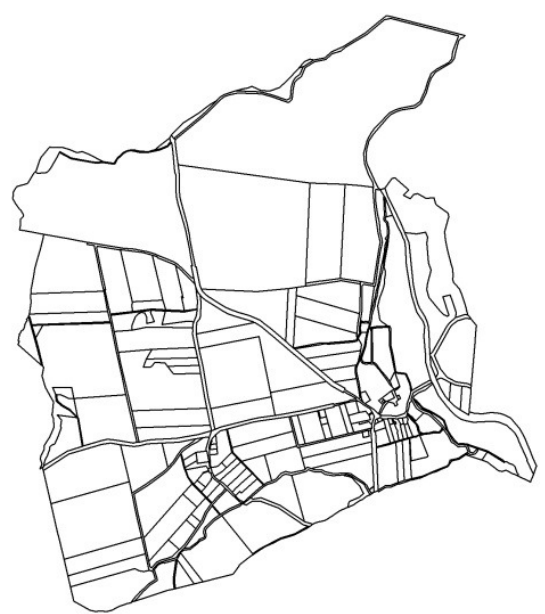

(a)

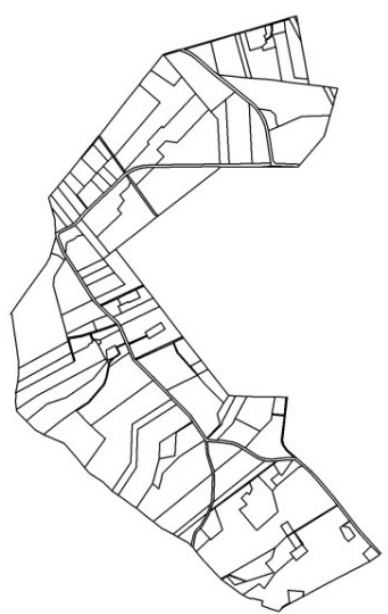

(b)

Fig. 2. Plot layout on the study villages: (a) Krajów; (b) Grabal 


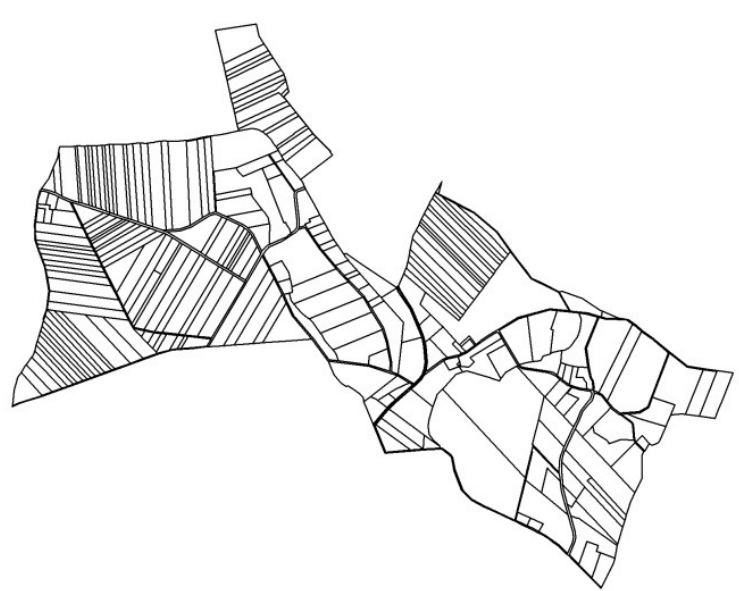

(c)

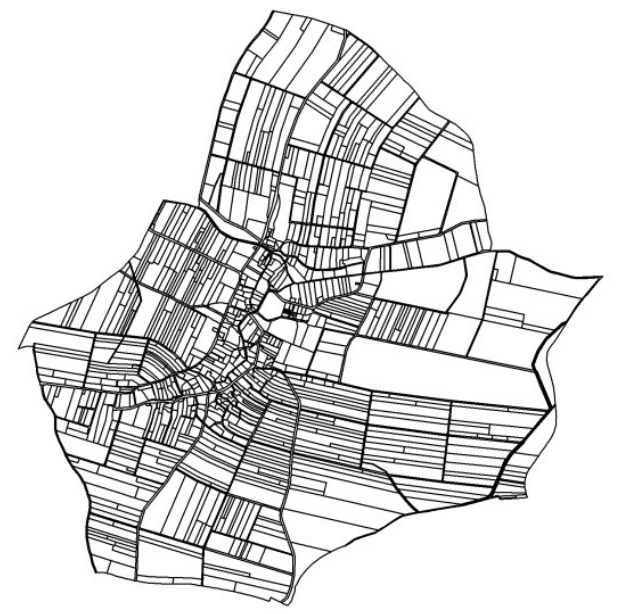

(d)

Fig. 2. Plot layout on the study villages: (c) Marysinek; (d) Rudołowice

All necessary data (geometrical and descriptive) was derived from Lands and Buildings Register in Poland, in the vector form.

\section{Methods}

Land fragmentation was analyzed using five morphometric measures of the parcels and information on parcel land use. The analyzed factors are as follows: area $(P A)$ and shape of parcel $(S I)$; number of parcel boundary points $(N o B P)$, dispersion of parcels $(D o P)$, land use on parcel $(P o A L$ and $P o B L)$ and parcel percentage of a whole holding area $(P P o H)$.

Shape of parcel was represented by the index $(S I)$ calculated on the basis of the Eqn (1).

$$
S I=\frac{4 \pi A_{i}}{p_{i}^{2}}
$$

where: $A_{i}$ - area of $i$ parcel; $p_{i}$ - perimeter of $i$ parcel. This index was used and recommended by [17]. The index has values between 0 and 1 , where 1 is the best shape, represented by a circle.

Number of boundary points $(N o B P)$ - the number of o parcel (polygon) vertex, defining the complexity of parcel. The factor may take value equal or greater than 3 .

Dispersion of parcels $(D o P)$ understands as distance of parcel from the holding center (human habitat). The distance is measured as a nearest path from parcel centroid to the holding center using the road network. This factor may take any positive value. A map illustrating this measure for one of the study villages is provided on Figure 3.

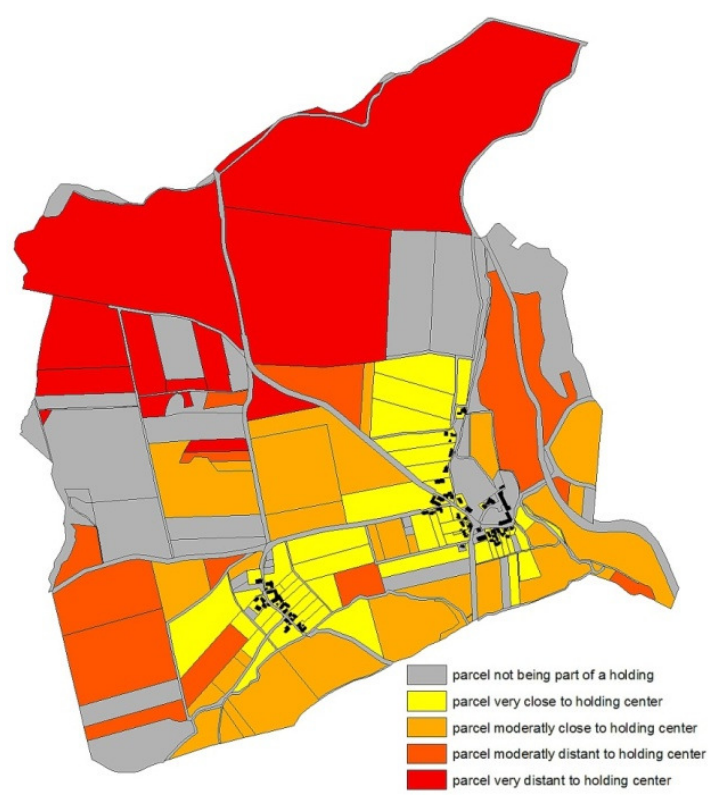

E3. Illustration of dispersion $(D o P)$ of parcels measure 
Land use was calculated as a specific land use percentage of a whole parcel area. There were two specific land use types considered: agriculture land which consist of arable land, pastures and orchards $(P O A L)$ and built-up land $(P o B L)$.

Parcel percentage of a whole holding area $(\mathrm{PPOH})$ was calculated as a quotient between parcel area and total area of holding to which the parcel belongs.

The proposed method of land fragmentation assessment is based either on the above measures computed for each parcel or on correlations between these measures.

\section{Results and discussion}

The mean values for all proposed measures for each study village were calculated and the results are shown in Table 2. On the basis of the individual measures several relationships has been discovered. First of all, the average parcel area $(P A)$ is relatively high in the village with low fragmentation and decreases with the growth of fragmentation degree. There are two measures indicating the shape of the parcel: shape index $(S I)$ and number of boundary points $(N o B P)$. The higher values of these indicators, the better shape the parcel. What is quite surprising, the $S I$ index does not show any variability among the study villages and for all of them oscillates between 0.5 and 0.55 . Therefore deciding is NoBP index. It takes highest average value in Krajów (the lowest fragmentation) and the lowest average value in Rudołowice (the highest fragmentation). The other measures don't show any ordered variability.

Table 2. The values of land fragmentation measures

\begin{tabular}{lllll}
\hline & Krajów & Grabal & Marysinek & Rudołowice \\
\hline PA $\left[\mathrm{m}^{2}\right]$ & 34293.76 & 25546.66 & 17995.21 & 6451.689 \\
NoBP & 14.24 & 10.80 & 10.47 & 9.892 \\
DoP & 521.11 & 332.45 & 462.77 & 378.307 \\
PoAL & 67.42 & 66.88 & 47.30 & 63.871 \\
PoBL & 17.41 & 8.30 & 7.36 & 27.993 \\
SI & 0.55 & 0.54 & 0.53 & 0.523 \\
PPoH & 30.17 & 37.65 & 16.00 & 54.418 \\
\hline
\end{tabular}

Because only two of the proposed measures are significant in assessing land fragmentation, the correlations matrixes between all the factors were created for each study village. The values of each correlation were compared among the villages and in case of some of them some significant ordered differences were identified. In all villages - what was predictable - parcel area has a strong positive correlation with number of boundary points and percentage of agriculture land has a strong negative correlation with percentage of built-up area and the distance of parcel from the holding center has a strong negative correlation with the percentage of built-up area on a parcel. But some of the correlation values vary depending on the study village in the specific order of degree of land fragmentation. Table 3 provides the selected correlations values between these measures, which seem to be significant. They are also illustrated on the plot provided on Figure 4.

Table 3. Values of selected correlations between land fragmentation measures

\begin{tabular}{lllll}
\hline & Krajów & Grabal & Marysinek & Rudołowice \\
\hline PA - SI & -0.04 & -0.13 & -0.16 & -0.41 \\
NoBP - DoP & 0.21 & -0.21 & -0.25 & -0.43 \\
NoBP - SI & -0.33 & -0.30 & -0.12 & 0.01 \\
PoAL - SI & 0.06 & 0.03 & -0.01 & -0.30 \\
PoBL - PPoH & 0.47 & 0.38 & 0.20 & 0.14 \\
\hline
\end{tabular}

The negative correlation between parcel area $(P A)$ and shape index of parcel $(S I)$ become higher with the higher fragmentation degree, just like correlation between percentage of agriculture land on a parcel $(P O A L)$ and shape index $(S I)$ and correlation between number of parcel boundary points $(N o B P)$ and dispersion of parcels $(D o P)$. Moreover, in the village with relatively low fragmentation the correlation between $N o B P$ and $D o P$ changes to significant positive value, which indicates that on less fragmented areas more complex parcels (with many boundaty points) are distant from the holding center. On the other hand, the correlation between number of parcel boundary points $(N o B P)$ and parcel shape index $(S I)$ is insignificant on the high-fragmented area and increases negatively with decrease of fragmentation degree. Finally, the correlation between percentage of built-up land on a parcel $(P o B L)$ and parcel percentage of a whole holding area $(P P o H)$ takes high values on less fragmented villages and tends to 0 with an increase of fragmentation degree. 


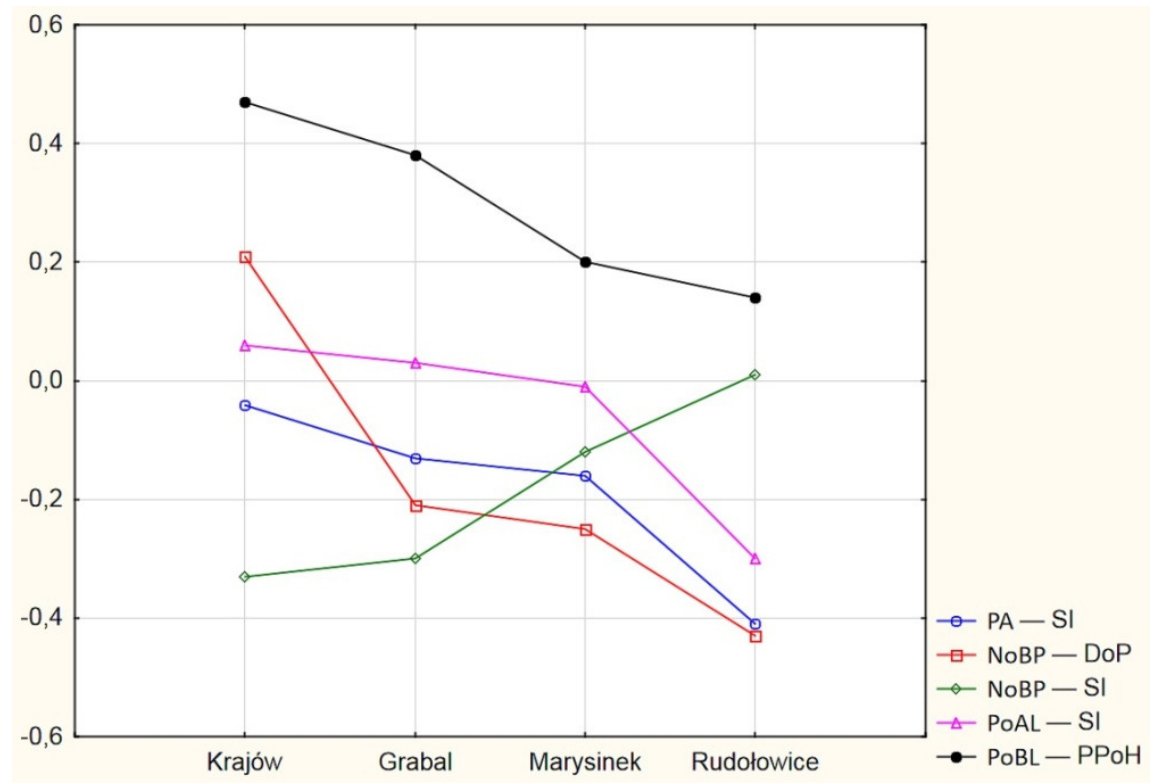

Fig. 4. Plot of the values of selected correlations between land fragmentation measures

Summarizing, low values of mean parcel area $(P A)$ and number of boundary points $(N o B P)$ indicate high land fragmentation on the given area. Moreover a strong negative correlations between parcel area $(P A)$ and shape index $(S I)$, number of boundary points $(N o B P)$ and dispersion of parcels $(D o P)$, percentage of agriculture land $(P o A L)$ and shape index $(S I)$ also suggest relatively high land fragmentation. On the other hand a strong positive correlation between percentage of built-up area $(\mathrm{PoBA})$ and parcel percentage of a holding $(\mathrm{PPoH})$, strong negative correlation between number of boundary points $(N o B P)$ and shape index $(S I)$ indicate an area characterized by relatively low land fragmentation.

\section{Conclusion}

The main problems associated with land fragmentation can be outlined as the dispersion, the small size and the irregular shape of land parcels. Thus it can be evaluated by morphometric measures, when the shape analysis of land parcels is of utmost importance. However, parcel shape indices have major deficiencies [9, 13]. The compound analysis of area, shape index, number of boundary points, distance from the holding center, land use on a parcel and total holding area still is not enough comprehensive to make reliable assessment. Inclusion of correlations between these measures gives interesting and more accurate results and seems to be enough information to assess land fragmentation.

On the other hand, the above analysis can be a contribution to the determination of the threshold values of the measures and correlations that indicate high land fragmentation or it can be even a basis for introducing a complex land fragmentation index, which could be computed on the basis on given measures and correlations. However, to develop such an index a deeper research has to be done and definitely much more various study data are needed - from well-organized and lowfragmented, to very complex and high-fragmented villages. Such a data contributions will allow for more reliable observation of the measures and correlations variability.

\section{Acknowledgements}

The research was conducted within the project N N526 160240 financially supported by the National Science Centre Poland (Narodowe Centrum Nauki).

\section{References}

[1] Bentley, J. W. 1987. Economic and Ecological Approaches to Land Fragmentation: In Defense of a Much-Aligned Phenomenon, Annual Review of Anthropology 16: 31-67. http://dx.doi.org/10.1146/annurev.an.16.100187.000335

[2] European Commission. 2005. Agricultural Statistics-Quarterly Bulletin: Special Issue-Frame Structure Survey 2003. Office for Official Publications of the European Communities. Luxemburg.

[3] FAO. 2003.Opportunities to mainstream land consolidation in rural development programmes of the European Union. Land Tenure Policy Series, Rome.

[4] King, R.; Burton, S. 1982. Land fragmentation: Notes on a fundamental rural spatial problem, Progress in Human Geography 6(4): 475-494.

[5] MacPherson; M. F. 1982. Land Fragmentation: A Selected Literature Review. Cambridge, Mass.: Harvard University, Harvard Institute for International Development.

[6] Blaikie, P.; Sadeque, A. 2000. Policy in the High Himalayas: Environment and Development in the Himalayan Region. Kathmandu: ICIMOD.

[7] van Dijk, T. 2003. Scenarios of Central European land fragmentation, Land Use Policy 20: 149-158. http://dx.doi.org/10.1016/S0264-8377(02)00082-0

[8] The World Bank. 2006. Three Pillars of Rural Development". The World Bank, Feb. 2006. 
[9] Demetriou, D.; Stillwell, J.; See, L. 2013a. A new methodology for measuring land fragmentation, Computers, Environment and Urban Systems 39: 71-80. http://dx.doi.org/10.1016/j.compenvurbsys.2013.02.001

[10] Van Hung, P.; MacAulay, G.; Marsh, S. 2007. The economics of land fragmentation in the North Vietnam, The Australian Journal of Agricultural and Resource Economics 51: 195-211. http://dx.doi.org/10.1111/j.1467-8489.2007.00378.x

[11] Pasakarnis, G.; Maliene, V. 2010. Towards sustainable rural development in Central and Eastern Europe: Applying land consolidation, Land Use Policy 27: 545-549. http://dx.doi.org/10.1016/j.landusepol.2009.07.008

[12] Pasakarnis, G.; Morley, D.; Maliene, V. 2013. Rural development and challenges establishing sustainable land use in Eastern European countries, Land Use Policy 30: 703-710. http://dx.doi.org/10.1016/j.landusepol.2012.05.011

[13] Demetriou, D.; Stillwell. J.; See, L. 2013b. A GIS-based shape index for land parcels, in Proc. Of the SPIE 8795, First International Conference on Remote Sensing and Geoinformation of the Environment (RSCy2013), 87951C (August 5, 2013). http://dx.doi.org/10.1117/12.2026499

[14] van Dijk, T. 2007. Complications for traditional land consolidationin Central Europe, Geoforum 38: $505-511$. http://dx.doi.org/10.1016/j.geoforum.2006.11.010

[15] Statistical Yearbook of Agricultural. 2012. Central Statistical Office. On-line: $\mathrm{http}: / /$ www.stat.gov.pl/cps/rde/xbcr/gus/rs_rocznik_rolnictwa_2012.pdf (accessed 09 December 2013).

[16] Woch, F. 2012. Możliwości wprowadzenia zintegrowanego rozwoju obszarów wiejskich do praktyki w Polsce, in Proc. of VI International Conference of Maloposkie Voivodship ,,Trends in amendment of the Act on land consolidation and exchange”, 20 November 2012 , Cracow, Poland.

[17] Aslan, T.; Gundogdu, K.; Arici I. 2007. Some metric indices for the assessment of land consolidation projects, Pakistan Journal of Biological Science 10: 1390-1397. http://dx.doi.org/10.3923/pjbs.2007.1390.1397 